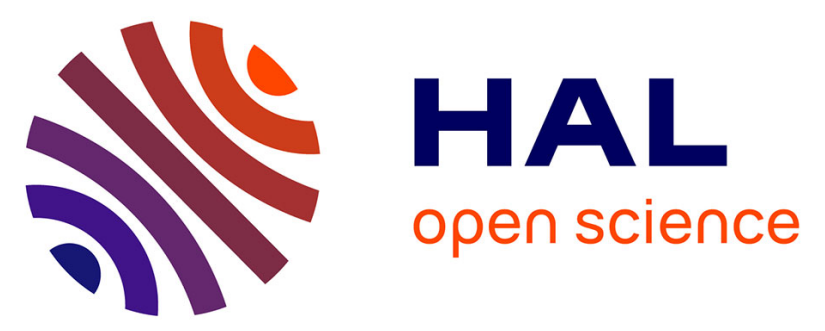

\title{
Investigating the growth of hyperbranched polymers by self-condensing vinyl RAFT copolymerization from the surface of upconversion nanoparticles
}

\author{
Alireza Kavand, Christian Blanck, Frédéric Przybilla, Yves Mély, Nicolas \\ Anton, Thierry Vandamme, Christophe Serra, Delphine Chan-Seng
}

\section{To cite this version:}

Alireza Kavand, Christian Blanck, Frédéric Przybilla, Yves Mély, Nicolas Anton, et al.. Investigating the growth of hyperbranched polymers by self-condensing vinyl RAFT copolymerization from the surface of upconversion nanoparticles. Polymer Chemistry, 2020, 11 (26), pp.4313-4325. 10.1039/d0py00452a . hal-02894296

\section{HAL Id: hal-02894296 https://hal.science/hal-02894296}

Submitted on 8 Jul 2020

HAL is a multi-disciplinary open access archive for the deposit and dissemination of scientific research documents, whether they are published or not. The documents may come from teaching and research institutions in France or abroad, or from public or private research centers.
L'archive ouverte pluridisciplinaire HAL, est destinée au dépôt et à la diffusion de documents scientifiques de niveau recherche, publiés ou non, émanant des établissements d'enseignement et de recherche français ou étrangers, des laboratoires publics ou privés. 


\title{
Investigating the growth of hyperbranched polymers by self-condensing vinyl RAFT copolymerization from the surface of upconversion nanoparticles
}

Alireza Kavand, ${ }^{\mathrm{a}, \mathrm{b}}$ Christian Blanck, ${ }^{\mathrm{a}}$ Frédéric Przybilla, ${ }^{\mathrm{c}}$ Yves Mély, ${ }^{\mathrm{c}}$ Nicolas Anton, ${ }^{\mathrm{b}}$ Thierry Vandamme, ${ }^{\mathrm{b}}$ Christophe A. Serra, ${ }^{a}$ Delphine Chan-Seng ${ }^{\mathrm{a},{ }^{*}}$

a Université de Strasbourg, CNRS, Institut Charles Sadron UPR 22, F-67000 Strasbourg, France

bUniversité de Strasbourg, CNRS, Laboratoire de conception et application de molécules bioactives UMR 7199, F-67000 Strasbourg, France

' Université de Strasbourg, CNRS, Laboratoire de bioimagerie et pathologies UMR 7021, F-67000

Strasbourg, France

This manuscript is a tribute to the 50 year anniversary of the French Polymer Group (Groupe Français des Polymères - GFP).

\begin{abstract}
Hyperbranched poly( $N$-(2-hydroxypropyl) methacrylamide)s grafted on upconversion nanoparticles (UCNPs) were prepared by surface-initiated self-condensing vinyl RAFT copolymerization from the surface of UCNPs modified with a RAFT chain transfer agent. The effect of the grafting density in RAFT chain transfer agent on UCNPS and the concentration in transmer were investigated. The propagation of the polymerization was strongly affected by termination and transfer reactions associated to the high local concentration in propagating chains due to the immobilization of the polymer chains at the surface of UCNPs and increased number of active centers during the polymerization, but also to the hopping and rolling mechanisms related to the surface-initiated RAFT polymerization. The development of such nanohybrids opens the way to novel nano-objects for biomedical imaging and theranostics.
\end{abstract}




\section{INTRODUCTION}

Hybrid materials are attractive to respond to the increasing demand for novel materials with well-defined properties. The preparation of hybrid materials based on polymers and inorganic nanoparticles has been investigated notably by encapsulation of inorganic nanoparticles in polymer particles and attachment of polymers at the surface of inorganic nanoparticles. ${ }^{1}$ In the latter case, the two main methods are the "grafting to" consisting of the reaction between orthogonal functional groups present on the polymer and at the surface of the nanoparticles and "grafting from" involving the polymerization of monomers from the surface of the nanoparticles. A wide range of inorganic nanoparticles ${ }^{2}$ have been used to grow polymers from their surface using different polymerization techniques such as cationic, ${ }^{3,4}$ anionic, ${ }^{5,6}$ and radical $^{7}$ polymerizations. These hybrid materials provide access to the compatibilisation of inorganic particles in polymer matrices, ${ }^{8}$ and enhancement of the nanoparticles stealthiness for biomedical applications. ${ }^{9}$

Lanthanide-doped upconversion nanoparticles (UCNPS), a new family of luminescent nanoparticles, have attracted considerable interest for the development of probes for bioimaging. ${ }^{10}$ UCNPs are able to convert near-infrared (NIR) excitation into visible and ultraviolet (UV-vis) emission upon excitation of a low intensity laser. ${ }^{11}$ This property, specific to UCNPs, is of interest for biomedical applications as it leads to low phototoxicity, no conflict with the autofluorescence of biological systems, and high optical penetration depth of light in biological tissues. ${ }^{12}$ Compared to organic dyes and quantum dots, UCNPs show sharp emission bandwidth, long luminescence decays, no photobleaching, and no photoblinking. Their properties, especially their dispersity in solution, can be tuned through the production of a polymer corona around UCNPs through ligand exchange, ${ }^{13,14}$ encapsulation in a polymer shell, ${ }^{15}$ and surface-initiated polymerization. The latter approach requires the introduction of functional groups at the surface of the nanoparticles to allow the growth from the surface. The functionalities at the surface of UCNPs have been tuned by either choosing the proper ligand during the synthesis of UCNPs to introduce the functional group promoting the polymerization (e.g. ricinoleic acid as ligand to introduce hydroxyl groups as initiating groups for the cationic ring-opening polymerization of glycidol ${ }^{16,17}$ ) or by modifying the functionalities present at the surface to insert the suitable functional group to induce polymerization from the surface (e.g. chain transfer agents for photoenergy/electron transfer-reversible additionfragmentation chain transfer radical polymerization affording linear poly(oligo(ethylene glycol) methacrylate)s, ${ }^{18}$ and $\alpha$-bromoisobutyryl groups to initiate the atom transfer radical polymerization (ATRP) of 4,5-dimethoxy-2-nitrobenzyl methacrylate ${ }^{19}$ ). 
Self-condensing vinyl polymerization (SCVP) was first introduced by the group of Fréchet ${ }^{20}$ consisting of using a vinyl (co)monomer possessing an initiating or chain transfer agent (inimer or transmer respectively) on its side chain to create branching points. The degree of branching (DB) can be tuned by changing the ratio between monomer and inimer/transmer. SCVP has been investigated through the three main controlled radical polymerization techniques, ${ }^{21}$ i.e. nitroxide-mediated polymerization, ATRP, and reversible addition-fragmentation chain transfer (RAFT) polymerization. The use of SCVP to grow hyperbranched polymers (HBPs) on nanoparticles has been mostly performed using ATRP from silica, ${ }^{22}$ and $\mathrm{ZnO}^{23}$ nanoparticles. ${ }^{24}$

Herein we report the growth of HBPs prepared by SCVP under RAFT conditions from the surface of UCNPs. To the best of our knowledge, SCVP under RAFT conditions has not been attempted on nanoparticles. The surface of UCNPs was modified by silanization to introduce functional groups permitting to covalently attach the anchoring groups that will mediate the polymerization. Various approaches have been reported in the literature to functionalize the surface to conduct surface-initiated RAFT polymerization including anchoring the initiator or RAFT chain transfer agent $(\mathrm{Z}-\mathrm{C}(=\mathrm{S}) \mathrm{S}-\mathrm{R})$ through its $\mathrm{R}$ - or Z-group to the surface with a strong preference for the anchoring of the chain transfer agent through its $R$ group ${ }^{7}$ that was adopted here. SCVP was investigated by varying the grafting density in chain transfer agent at the surface of UCNPS and the ratio of transmer to monomer and comparing to the results to those for the preparation of linear polymers.

\section{RESULTS AND DISCUSSION}

\section{Preparation of UCNPs with a well-defined density of RAFT chain transfer agents at their surface} Monodispersed spherical $\beta-\mathrm{NaYF}_{4}: \mathrm{Yb}^{3+}, \mathrm{Er}^{3+}$ nanocrystals (UCNP@OA) with a diameter of $27.2 \pm 0.4 \mathrm{~nm}$ were prepared by co-precipitation method using oleic acid as capping agent according to the protocol described by $\mathrm{Li}$ et $a .^{25}$ and characterized by high-resolution transmission electron microscopy (HR-TEM), dynamic light scattering (DLS), X-ray diffraction and luminescence measurements (Fig. S1). The surface of UCNP@OA was modified to create a silica shell possessing amine groups at their surface (UCNP@NH by reverse microemulsion technique ${ }^{26}$ through the successive condensation of tetraethylorthosilicate and (3-aminopropyl) triethoxysilane (APTS). The formation of the silica shell was confirmed by i) HR-TEM showing a silica shell of $8.1 \pm 0.5 \mathrm{~nm}$ around the UCNPs, ii) DLS showing monomodal peaks without aggregates with an increase in hydrodynamic diameter $\left(D_{h}\right)$ from 22 to $45 \mathrm{~nm}$ (values in number, Fig. S2a), and iii) Fouriertransform infrared (FT-IR) spectroscopy exhibiting the characteristic stretching peak of -Si-O-Si-groups at $1062 \mathrm{~cm}^{-1}$. The presence of amine groups on the nanoparticles was 
identified at $1650 \mathrm{~cm}^{-1}$ ( $\mathrm{NH}$ in-plane stretching) and $3420 \mathrm{~cm}^{-1}\left(\mathrm{NH}_{2}\right)$ on the FT-IR spectrum and supported by a positive Kaiser test ${ }^{27}$ (Fig. S3). The surface specific area of UCNP@NH 2 was determined by establishing the nitrogen adsorption/desorption isotherms according to the Brunauer-Emmet-Teller (BET) theory (Fig. S4) and resulted in a value of $45.44 \pm$ $0.15 \mathrm{~m}^{2} \mathrm{~g}^{-1}$ (for $30 \mathrm{mg}$ of UCNP@ $\mathrm{NH}_{2}$, the surface area could be estimated to $1.4 \mathrm{~m}^{2}$ ). These nanoparticles, dispersible in water, ethanol, acetone, and DMF, were prepared with different amounts of APTS (i.e. 38, 76, and $152 \mu \mathrm{mol}$ of APTS for $80 \mathrm{mg}$ of UCNP@OA) to vary the grafting density in amine groups at the surface of UCNPs. A carboxylic acidterminated RAFT chain transfer agent, suitable for the polymerization of methacrylates, 4-cyano-4-(thiobenzoylthio)pentanoic acid (CPABD), was coupled to the amine groups present at the surface of UCNPs using $N, N, N^{\prime}, N^{\prime}$-tetramethyl-O-(1H-benzotriazol-1yl)uronium hexafluorophosphate as coupling agent in the presence of 1-hydroxybenzotriazole hydrate and diisopropylethylamine in DMF (Scheme 1). The color of the UCNPs changed from white to red corresponding to the color of CPABD (Fig. 1c). UCNP@CPABD were characterized by FT-IR spectroscopy (Fig. 1a) showing the characteristic stretching absorption band of nitrile groups at $2160 \mathrm{~cm}^{-1}$ and UV-vis spectroscopy as a suspension in ethanol exhibiting the strong absorption of the thiocarbonyl group at $315 \mathrm{~nm}$ (Fig. 1b) confirming the presence of CPABD at the surface of UCNPs. ${ }^{28}$ The grafting density in CPABD attached to UCNPs was determined by TGA ${ }^{18,}$ ${ }^{29}$ (Fig. S5) as 0.6, 1.4 and 3.1 CPABD per square nanometer of UCNPs for UCNP@CPABD low, UCNP@CPABD medium, and UCNP@CPABD high respectively (Table S1).

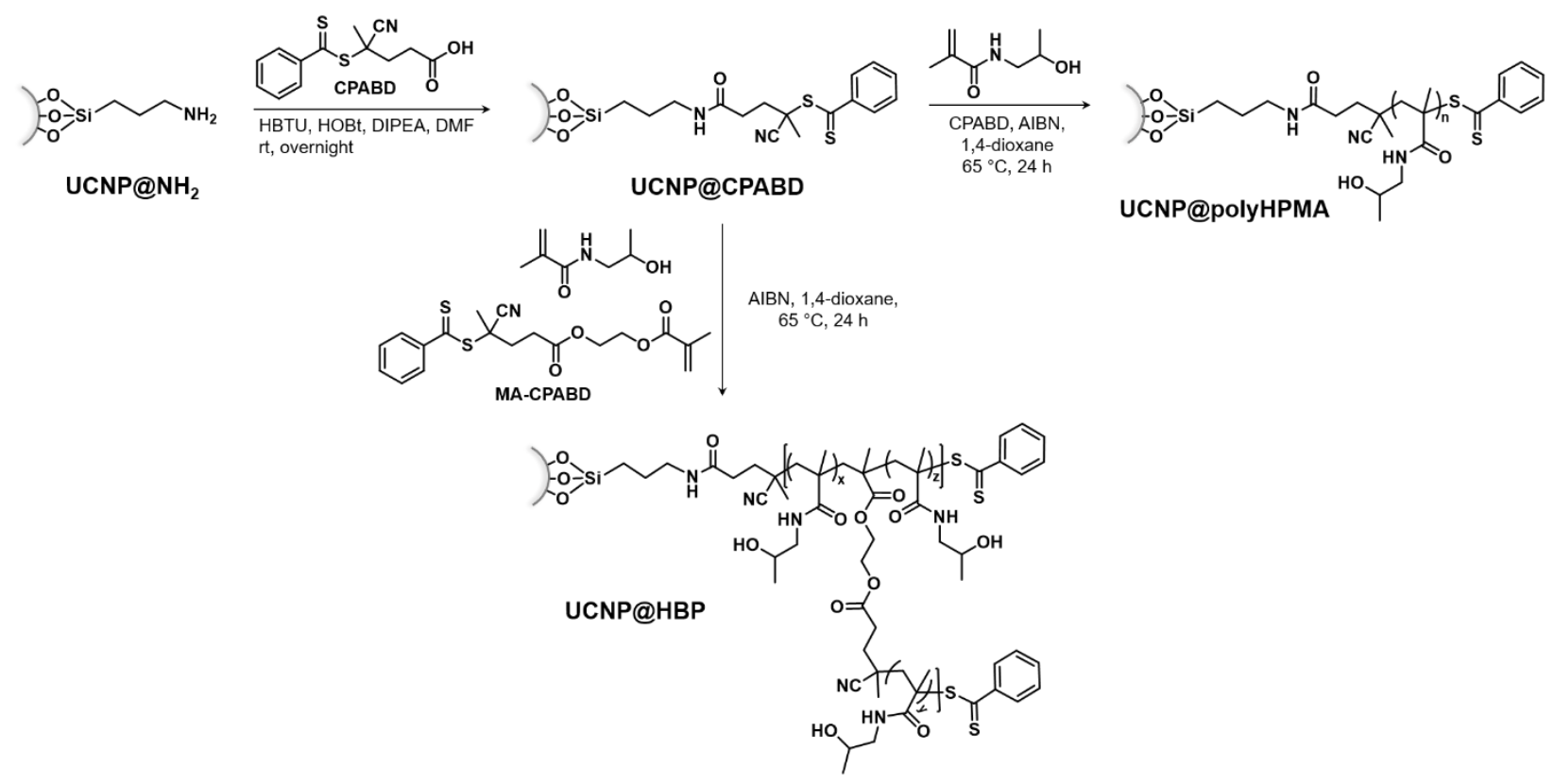

Scheme 1. Synthesis of UCNP@CPABD and its use to prepare linear (UCNP@polyHPMA) and hyperbranched (UCNP@HBP) poly(N-(2-hydroxypropyl) methacrylamide) grafted on UCNPs. 


\section{Polymerization of $\boldsymbol{N}$-(2-hydroxypropyl) methacrylamide from the surface of UCNP@CPABD}

$\operatorname{Poly}\left(N\right.$-(2-hydroxypropyl) methacrylamide) is commonly used to prepare drug conjugates ${ }^{30,} 31$ leading our choice to $\mathrm{N}$-(2-hydroxypropyl methacrylamide) (HPMA) as monomer for this study. The nature of the solvent is crucial especially because the polymerization was performed at the surface of UCNPS. Various reports highlight the effects of surface confinement and diffusion of monomers towards the propagating chains grafted on a surface emphasizing the importance of the solvent quality to perform a surface-initiated controlled radical polymerization. ${ }^{32,33}$ Linear poly(N-(2-hydroxypropyl) methacrylamide) (polyHPMA) were first prepared from the surface of UCNP@CPABD (Scheme 1) considering DMF, 1,4-dioxane, and $\mathrm{MeOH}$ as solvent for the polymerization.

The polymerization of HPMA from UCNP@CPABD was conducted in an oil bath thermoregulated at $65^{\circ} \mathrm{C}$ fixing the concentration in nanoparticles to $10 \mathrm{mg} \mathrm{mL}^{-1}$ and the monomer concentration to $0.57 \mathrm{M}$ using a molar ratio between HMPA, CPABD and 2,2'-azobis(isobutyronitrile) (AIBN) as initiator of 200:1:0.2. HPMA conversion was determined by ${ }^{1} \mathrm{H}$ NMR spectroscopy by comparing the integrations of the vinylic proton at $5.7 \mathrm{ppm}$ to the methyl protons of the polymer backbone at 0.5-1.1 ppm. The polymerization of HPMA seemed to be more suitable when conducted in 1,4-dioxane rather than in $\mathrm{MeOH}$ and DMF. HPMA conversion after $21 \mathrm{~h}$ of polymerization from UCNP@CPABD high $_{\text {reached }} 18 \%$ in 1,4-dioxane compared to 7\% in DMF and MeOH. TGA indicated a content in polyHPMA of 25 and 6 wt\% using UCNP@CPABD high and UCNP@CPABD low respectively for the polymerization in 1,4-dioxane and almost no polymer formation on UCNPs for the polymerizations in DMF and $\mathrm{MeOH}$ (Fig. S6). No significant visual differences were observed for the dispersions of UCNP@CPABD in 1,4-dioxane and DMF, however their dispersibility in methanol was visually observed to be poor. The formation of aggregates could lead to the low accessibility of HPMA to the chain transfer agents grafted at the surface of UCNPs. Pan et al. investigated the polymerization of HMPA in different organic solvents including DMF. ${ }^{34}$ The kinetic plot $\left(\ln \left([\mathrm{M}]_{0} /[\mathrm{M}]\right.\right.$ vs. time) exhibited a deviation from linearity that was attributed to a decrease in propagating chains due to termination reactions. It seems that using 1,4-dioxane led to a lower probability of termination reactions. 

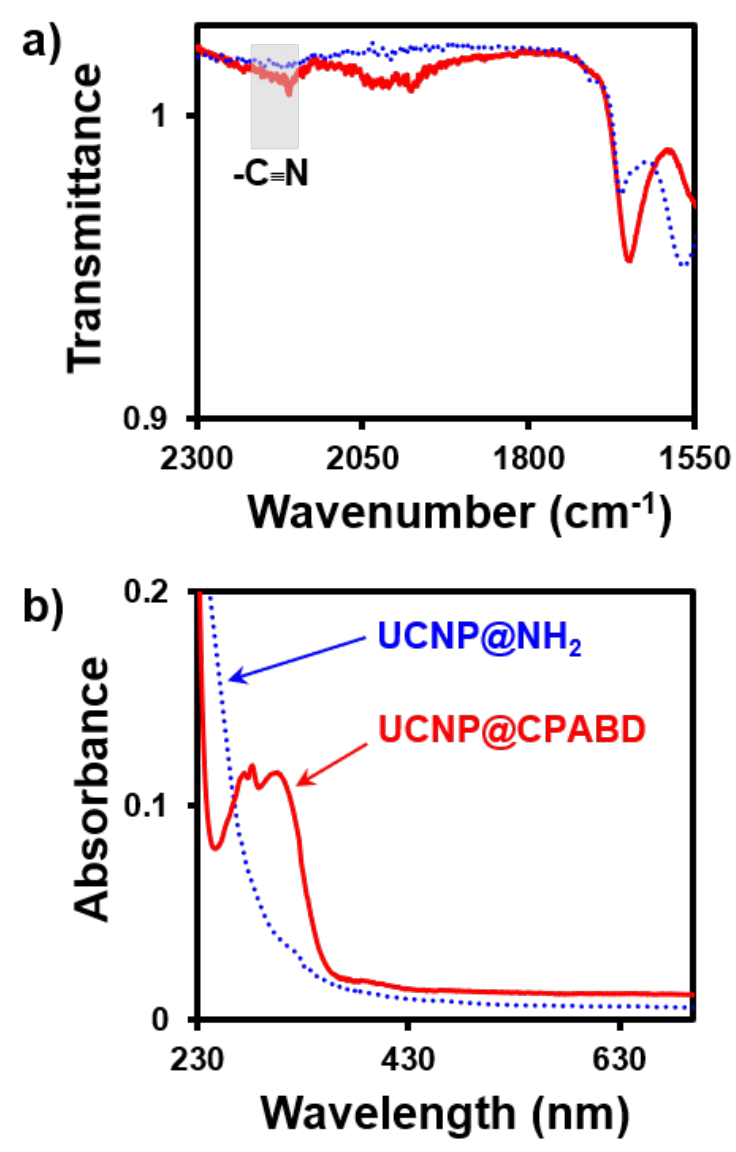

c)

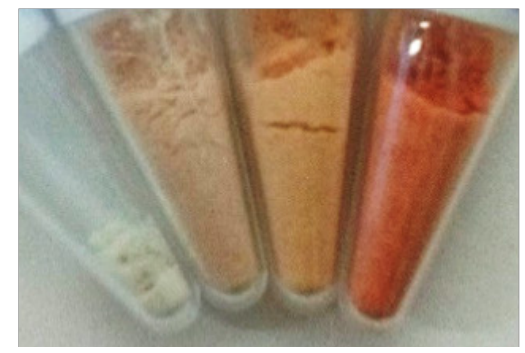

Fig. 1 Characterization of UCNP@CPABD by (a) FT-IR, and (b) UV-vis spectroscopies, along with the (c) observation of the color change of the UCNP powders according to the grafting density in CPABD (from left to right: UCNP@NH2, UCNP@CPABD low, UCNP@CPABD medium, UCNP@CPABDhigh).

\section{Self-condensing vinyl copolymerization from the surface of UCNP@CPABD}

HBPs grafted on UCNPs were prepared by self-condensing vinyl copolymerization of HPMA with a methacrylate-based transmer bearing CPABD, 2-(methacryloyloxy)ethyl-4-cyano-4-((phenylcarbonothioyl)thio)pentanoate ${ }^{35}$ (MA-CPABD) inducing the formation of branching points (Scheme 1c). The polymerization was conducted in 1,4-dioxane in an oil bath thermoregulated at $65{ }^{\circ} \mathrm{C}$ for $24 \mathrm{~h}$ using UCNP@CPABD high $\left(10 \mathrm{mg} \mathrm{mL}^{-1}\right)$, HPMA $(0.56 \mathrm{M})$ and a molar ratio between HMPA, MA-CPABD and AIBN of 200:1:0.2. The consumption of MA-CPABD to form the HBP was observed by the decrease in the pink color of the polymerization solution (Fig. 2, inset photo) and 
reached a monomer conversion of $18 \%$ determined gravimetrically (compared to $21 \%$ for the preparation of polyHPMA under the same conditions). After cleavage of the polymer from the surface of UCNPs by treatment with HF, its number-average molecular weight was determined by size-exclusion chromatography (SEC) as $220 \mathrm{~kg} \mathrm{~mol}^{-1}$ with a dispersity ( $\Theta$ ) of 6.75 as compared to $1794 \mathrm{~kg} \mathrm{~mol}^{-1}$ and 3.15 respectively for polyHMPA. As the same ratio of UCNP@CPABD ${ }_{\text {high }}$ and HPMA were used in both cases, it would have been expected that similar molecular weights would have been observed. However, the HBP had a lower molecular weight and higher dispersity, which could be attributed to the mechanism of RAFT polymerization from a surface and the increased steric hindrance due to the synthesis of HBP on a surface.

If the polymerization was living, all the terminal points of the HBP should possess a CPABD group and the number of CPABD groups should be correlated to the number of branching points (i.e. for $n$ CPABD terminal groups, the HBP would have ( $n-1)$ branching points). Due to i) the steric hindrance induced by the presence of polymer chains on UCNPs hindering the access to all CPABD, ii) the necessity of the monomer to diffuse towards the active centers present at the surface of UCNPs, and iii) the transfer of CPABD between active and dormant chains that are in close proximity, the number of branching points may be underestimated by considering the amount of CPABD. However, it is not possible to determine directly the number of branching points. The determination of the amount of CPABD incorporated in the HBP grafted on UCNPs (UCNP@HBP) was first attempted by ${ }^{1} \mathrm{H}$ NMR spectroscopy on the cleaved HBPs. However, the characteristic peaks of the branching points and the terminal CPABD groups were difficult to identify due to their low content on the HBP and the potential hydrolysis of the thioester groups during the cleavage of the HBPs from the surface of UCNPs with HF. Thiocarbonyl end groups show $\pi \rightarrow \pi^{*}$ and $\mathrm{n} \rightarrow \pi^{*}$ absorption bands in the UV and visible range respectively (300 and $515 \mathrm{~nm}$ for CPABD). ${ }^{36}$ As the direct quantification of CPABD groups present on UCNP@HBP by UV-vis spectroscopy could not be achieved due to the scattering interference of UCNP@polymer, the number of CPABD groups in the supernatant after $24 \mathrm{~h}$ of polymerization was determined using this technique and compared to a control solution consisting in the same initial concentration of CPABD in MeOH (i.e. $3 \mathrm{mM}$ ). The decrease of the absorption at $515 \mathrm{~nm}$ (Fig. 2a) was associated to the incorporation of $140 \mu \mathrm{mol}$ of MA-CPABD on the grafted HBP per gram of UCNPs and thus the formation of branching points on the polymer. To confirm our observation, the same experiment was conducted for the synthesis of a linear polymer on UCNPs (Fig. 2b), indicating a constant concentration in CPABD and confirming the stability of the RAFT chain transfer under the polymerization conditions used. The number of micromoles of CPABD on UCNP@HBP per gram of UCNP $(\mathrm{m})$, the number of branching points per polymer chain assuming a constant branching length, ${ }^{37}$ the degree of branching (DB), and the grafting density (number of 
polymer chains per $\mathrm{nm}^{2}$ of UCNP, $\sigma$ ) were estimated using Equations 1, 2, 3 and $4^{38,} 39$ respectively as $140,122,0.17$, and 0.014 chain per $\mathrm{nm}^{2}$ using UCNP@CPABD high. $_{\text {. }}$

$$
\mathrm{m}=\frac{\left[\mathrm{n}_{0}-\mathrm{n}_{\mathrm{s}}\left(\mathrm{n}_{\text {control }} \times \frac{\mathrm{A} 2}{\mathrm{~A} 1}\right)\right]}{\mathrm{m}_{\text {UCNP }}}
$$

Equation 1

where $m$ is the molality of CPABD for UCNP@HBP (i.e. number of moles of CPABD on UCNP@HBP per gram of UCNP), $n_{0}$ and $n_{s}$ the number of moles of MA-CPABD in solution at $t=0$ and $24 \mathrm{~h}$ respectively, $n_{\text {control }}$ the number of moles of CPABD in the control experiment, $A_{1}$ and $A_{2}$ the absorbance of MA-CPABD for the control solution and supernatant after polymerization respectively, and mucNP the mass of UCNP used.

branching point per chain $=\frac{M_{n}}{\frac{n_{1}}{n_{2}} \times M}$

Equation 2

where $M_{n}$ is the number-average molecular weight of the polymer grafted on UCNPs determined by SEC, $n_{1}$ the number of moles of HPMA per gram of UCNPs calculated from TGA, $n_{2}$ the number of moles of MA-CPABD per gram of UCNPs calculated from UV-Vis spectroscopy and M the molecular weight of HPMA as repeating unit (143.1 $\left.\mathrm{g} \mathrm{mol}^{-1}\right)$.

$\mathrm{DB}=\frac{2 \mathrm{D}}{2 \mathrm{D}+\mathrm{L}}$

Equation 3

where $D$ is the total number of branching units derived from MA-CPABD, and $L$ the total number of linear repeat units derived from HPMA consumption. The factor of 2 in Equation 3 is related to the fact that each branching unit induces the formation of two active centers and thus two branches. ${ }^{37,} 40$ The value for $D$ was determined by UV-vis spectroscopy considering the absorbance at $515 \mathrm{~nm}$ corresponding to the thiocarbonyl group of MA-CPABD (based on its number of moles per gram of UCNPs), while $L$ was calculated from TGA measurement (based on its number of moles of HPMA per gram of UCNPS).

$\sigma=\frac{\left(w / M_{n, U C N P}\right) \times N_{a}}{m_{U C N P} \times S_{U C N P}}$

Equation 4

where $w$ is the weight loss determined by TGA measurement, $M_{n, U C N P}$ the number-average molecular weight of the polymer grafted on UCNP determined by SEC analysis, $\mathrm{N}_{\mathrm{a}}$ the Avogadro number, mUCNP the weight of UCNP and SUCNP the specific surface area of UCNP calculated by BET analysis. 

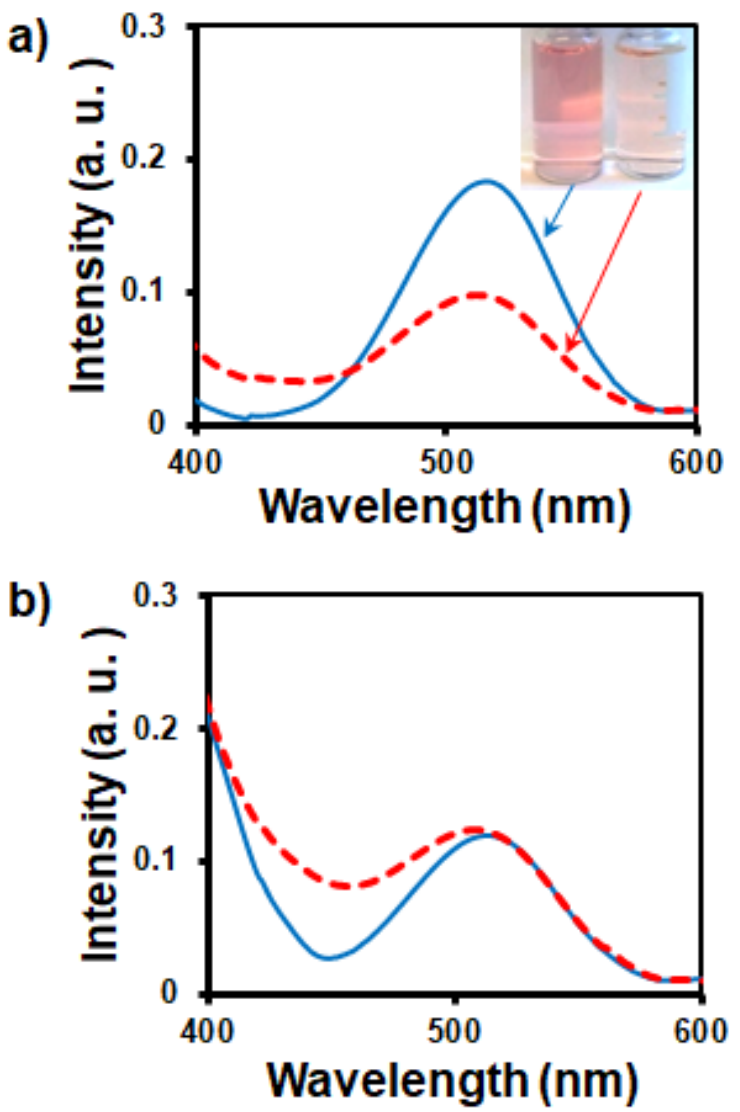

Fig. 2 UV-spectra of decanted solution after $24 \mathrm{~h}$ of polymerization (red dashed line) and control solution (blue solid line) using UCNP@CPABD high for the preparation of (a) HBP with HPMA:MA-CPABD:AIBN = 200:1:0.2 (inset photo of the control and polymerization solution after $24 \mathrm{~h}$ ) and (b) linear polymer with HPMA:CPABD:AIBN = 200:1:0.2.

DLS characterization of UCNP@HBP indicated a $\mathrm{D}_{\mathrm{h}}$ of $141 \mathrm{~nm}(\mathrm{PDI}=0.087)$ corresponding to a polymer corona of $27 \mathrm{~nm}$ considering the $\mathrm{D}_{\mathrm{h}}$ of UCNP@ $\mathrm{NH}_{2}$ of $87 \mathrm{~nm}$. UCNP@polyHPMA exhibited a larger polymer corona of $82 \mathrm{~nm}\left(D_{h}=251 \mathrm{~nm}, \mathrm{PDI}=0.258\right.$, Fig. S7) that could be associated to the higher molecular weight observed for this system as compared to the hyperbranched one. TGA revealed a lower content in polymer when preparing HBP from the surface of UCNPs as compared to the linear ones (Fig. 3) with an estimation of 1.4 and $3.4 \mathrm{mmol}$ of HPMA units per gram of UCNPs for the HBP and linear polymer respectively. The dispersion of UCNP@polyHPMA and UCNP@HBPhigh at a concentration of $0.5 \mathrm{mg} \mathrm{mL}^{-1}$ seemed both stable without observation of sedimentation within $24 \mathrm{~h}$. 


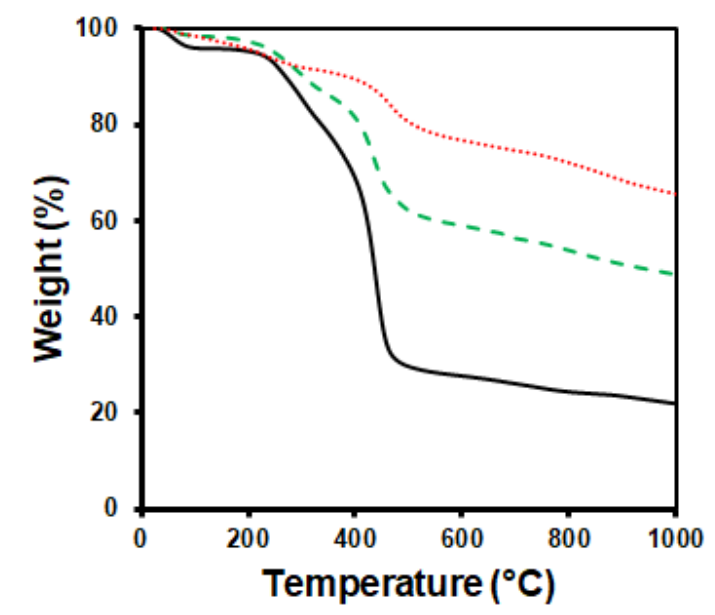

\begin{tabular}{lcc}
\hline UCNPs & $\begin{array}{c}\text { Char } \\
\text { (wt\%) }\end{array}$ & $\begin{array}{c}\text { Organic content in } \\
\text { nanohybrid (wt\%) }\end{array}$ \\
\hline UCNP@CPABD & 75 & 22 \\
UCNP@polyHPMA & 22 & 69 \\
UCNP@HBP & 49 & 40
\end{tabular}

Fig. 3 TGA of UCNP@CPABD (red dotted line), UCNP@polyHPMA (black solid line), and UCNP@HBP (green dashed line). The polymers were prepared from UCNP@CPABD high using 3 mM of CPABD and MA-CPABD for the linear and hyperbranched polymers respectively.

\section{Effect of the grafting density in CPABD on UCNPs}

The results from SEC and TGA measurements both suggested that the growth of HBPs from UCNPs under these conditions were hindered as compared to linear polymers. The migration of chain transfer agents when performing surface-initiated RAFT polymerization to obtain linear polymers has been reported to lead to termination and transfer reactions. ${ }^{41-43}$ Furthermore, the synthesis of hyperbranched structures induces steric hindrance that can affect the proper propagation of the polymer chains and thus enhance the propensity of termination and transfer reactions especially because the concentration of CPABD at the surface of UCNPs is locally high. The grafting density in CPABD on UCNPs was therefore investigated considering the selfcondensing vinyl copolymerization from UCNP@CPABD medium and UCNP@CPABD presence of $3 \mathrm{mM}$ of MA-CPABD. According to UV-vis spectroscopy, the number of branching points incorporated on the HBP grafted on UCNPs was 140, 90 and $34 \mu \mathrm{mol}$ per gram of UCNP@HBP for HBP prepared from UCNP@CPABD high, UCNP@CPABD medium and UCNP@CPABD low respectively. TGA of UCNP@HBPs (Fig. S8 and S9) indicated that the weight percentage of organic content grafted on UCNP from UCNP@CPABD medium was higher than for the nanohybrids obtained from UCNP@CPABD high indicating a higher consumption of HMPA and thus a lower DB (i.e. 0.14 and 0.05 for the HBP obtained from UCNP@CPABD ${ }_{\text {high }}$ and UCNP@CPABD medium respectively). The termination and transfer reactions seemed less pronounced with the decrease of the grafting density in CPABD affording a higher conversion of 
HMPA. The number of branching points per HBP chain was determined as 148 and 6 for UCNP@CPABD medium and UCNP@CPABD low respectively as compared to 122 for UCNP@CPABD high. The calculation of the grafting density (?]? revealed that UCNP@CPABD ${ }_{\text {high }}$ and UCNP@CPABD medium had very low densities estimated as 0.014 and 0.007 chain per $\mathrm{nm}^{2}$ respectively, while the one of UCNP@CPABD low was higher $\left(0.06\right.$ chain per $\mathrm{nm}^{2}$ ). These results suggested that transfer reactions for UCNP@CPABD high and UCNP@CPABD medium were more pronounced at the surface of UCNPs leading to a higher proportion of dead chains. ${ }^{42}$

As initiation takes place in solution in our system, the propagating chains can either consume HMPA and MA-CPABD in solution leading to HBP formed in solution or go through a chain transfer reaction with the CPABD present at the surface of UCNPs creating an active center to grow a HBP at the surface of UCNPs. The HBP formed in solution is expected to be less affected by termination and transfer reactions as the concentration in active centers will be lower as compared to the HBP immobilized on UCNPs. To better understand the polymerization behavior, the polymer grafted on UCNPs and formed in solution during the polymerization were both characterized by SEC. The polymer formed in solution had a lower number-average molecular weight as compared to the polymer formed at the surface of UCNPs (Fig. 4), i.e. 20 and $13 \mathrm{~kg} \mathrm{~mol}^{-}$ $1(\boxminus=3.88$ and 12.86$)$ respectively for polymers obtained from UCNP@CPABD medium and UCNP@CPABD high in solution compared to 839 and $220 \mathrm{~kg} \mathrm{~mol}^{-1}(\Theta=4.17$ and 6.75 ) respectively for polymers grafted on UCNPs. The molecular weights of the polymers formed in solution were lower than the calculated ones with relatively low dispersity, which could be attributed to cyclization reactions as previously reported in the literature. ${ }^{44,45}$ However, the polymers formed at the surface of UCNPs had a higher molecular weight and a broader molecular weight distribution that could be due to the high concentration in radicals per polymer chain leading to irreversible termination reactions notably between neighboring propagating chains. The higher the grafting density in CPABD on UCNPS, the more pronounced the termination reactions. Further lowering of the grafting density in CPABD, i.e. using UCNP@CPABD ${ }_{\text {low }}$ afforded polymers grafted on UCNPs with a lower molecular weight $\left(\mathrm{M}_{\mathrm{n}}=19 \mathrm{~kg} \mathrm{~mol}^{-1}\right)$ and narrower molecular weight distribution $(\Theta=1.65)$, closer to the characteristics of the polymer obtained in solution. It indicated a lower contribution of the termination and transfer reactions associated to the surface-initiated self-condensing vinyl RAFT copolymerization, for which CPABD were anchored at the surface of UCNPs inducing a high localized concentration in RAFT chain transfer agents. In solution, this phenomenon is less pronounced due to the homogeneous and lower localized concentration in RAFT chain transfer agent. ${ }^{46}$ 
a)

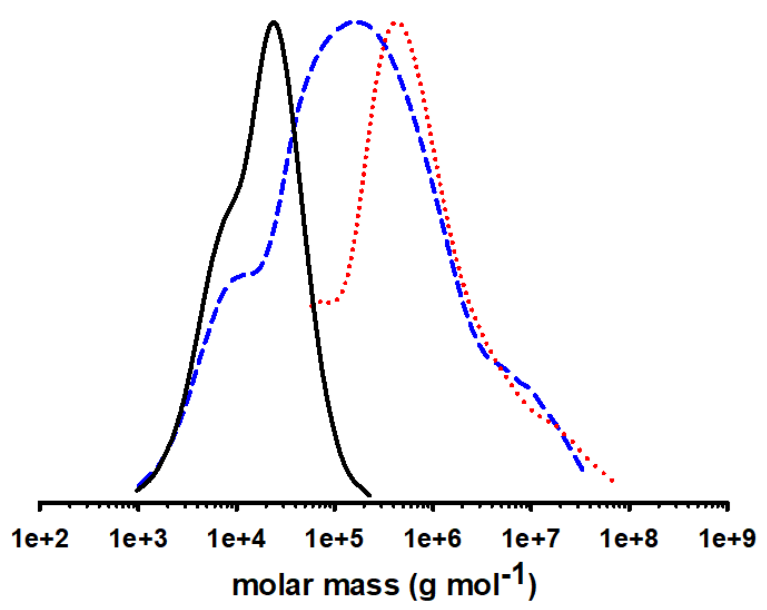

b)

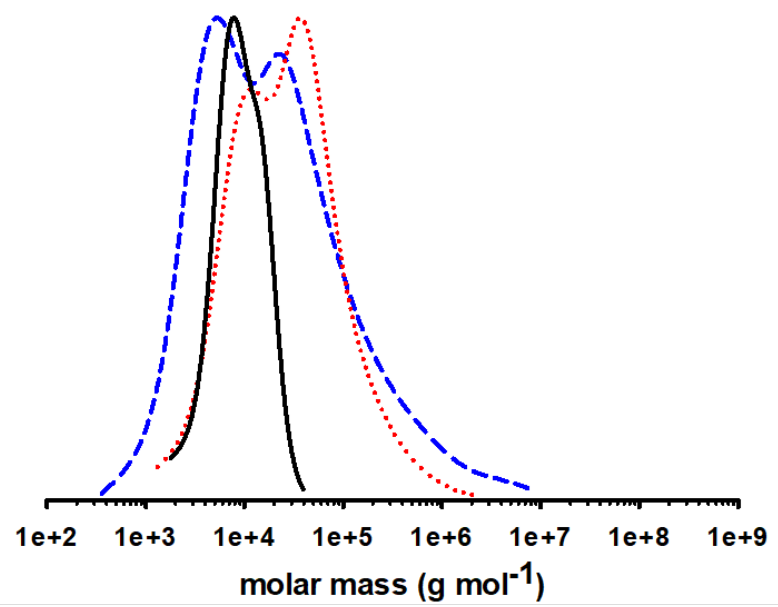

Fig. 4 Normalized SEC traces for HBPs (a) grafted on UCNPs and (b) formed in solution prepared using 3 mM of MACPABD from UCNP@CPABD low (black solid line), UCNP@CPABD medium (red dotted line), and UCNP@CPABD high (blue dashed line).

\section{Effect of the concentration in MA-CPABD transmer}

Considering UCNP@CPABD low, the concentration of MA-CPABD used during the polymerization was increased to $6 \mathrm{mM}$ to determine its effect on the HBP formed at the surface of UCNPs. According to UV spectroscopy, the number of MA-CPABD incorporated as branching points increased from 34 to $67 \mu \mathrm{mol}$ per gram of UCNP for 3 and $6 \mathrm{mM}$ of MA-CPABD used for the polymerization. TGA measurement permitted to determine the content of HPMA as $0.52 \mathrm{mmol}$ per gram of UCNP, which was close to the value obtained for the HBP prepared with $3 \mathrm{mM}$ of MA-CPABD (i.e. $0.68 \mathrm{mmol}$ ). Thus, DB increased from 0.08 to 0.19 when doubling the amount of MA-CPABD used. SEC measurements (Fig. 5) indicated a decrease of the number-average molecular weight with the increase of the concentration in MA-CPABD, i.e. $19 \mathrm{~kg} \mathrm{~mol}^{-1}$ in the case of $3 \mathrm{mM}$ of MA-CPABD compared to $11 \mathrm{~kg} \mathrm{~mol}^{-1}$ when using $6 \mathrm{mM}$ of MA-CPABD, with a decrease of the dispersity from 1.65 to 1.55 respectively. Under the same polymerization conditions ( $3 \mathrm{mM}$ 
of CPABD), polyHPMA had a lower number-average molecular weight $\left(9 \mathrm{~kg} \mathrm{~mol}^{-1}\right)$ and narrower molecular weight distribution $(\Theta=1.46)$. The number of branches per polymer chain was calculated as 6 and 9 for $3 \mathrm{mM}$ and $6 \mathrm{mM}$ of MA-CPABD respectively. The grafting density of polymer was determined as 0.06 chain per $\mathrm{nm}^{2}$ for $3 \mathrm{mM}$ of MA-CPABD, which was similar to the one using $6 \mathrm{mM}$ of MA-CPABD (i.e. 0.07 chain per $\mathrm{nm}^{2}$ ). However, when preparing linear polymer from UCNPs under the same conditions, the number of polymer chains was 0.11 chain per $\mathrm{nm}^{2}$, which was twice as compared to the HBP. The three-dimensional structure of HBPs affected strongly the propagation of the polymer chains from the surface of UCNPs inducing steric hindrance and enhancing the probability of termination and transfer reactions. These phenomena illustrated in Fig. 6 would not only decrease the grafting density, but also increase the dispersity of the polymer formed ${ }^{33,47}(\bigoplus=1.46$ and 1.65 for polyHPMA and UCNP@CPABD high, and 44 and 19 wt\% for UCNP@CPABD medium respectively) that was attributed to the enhancement of termination and transfer reactions due to the increased grafting density in $\mathrm{CPABD}^{46,48,49}$ on UCNPs and the higher amount of terminal active centers. In summary, the ratio between the molecular weight of the HBP formed on UCNPs and in solution significantly increased with the increase in grafting density of CPABD on UCNPs (Fig. 7a). The effect of the concentration of MACPABD (Fig. 7b) had a less pronounced influence on the difference in molecular weight between the HBP formed on UCNPs and in solution, while for polyHMPA ([MA-CPABD] $=0 \mathrm{mM}$ ) this difference was minimal. This phenomenon could be attributed to the higher probability of coupling reactions between propagating chains for HBPs as compared to linear polymers due to their higher number of terminal active centers and their closer spatial proximities. 

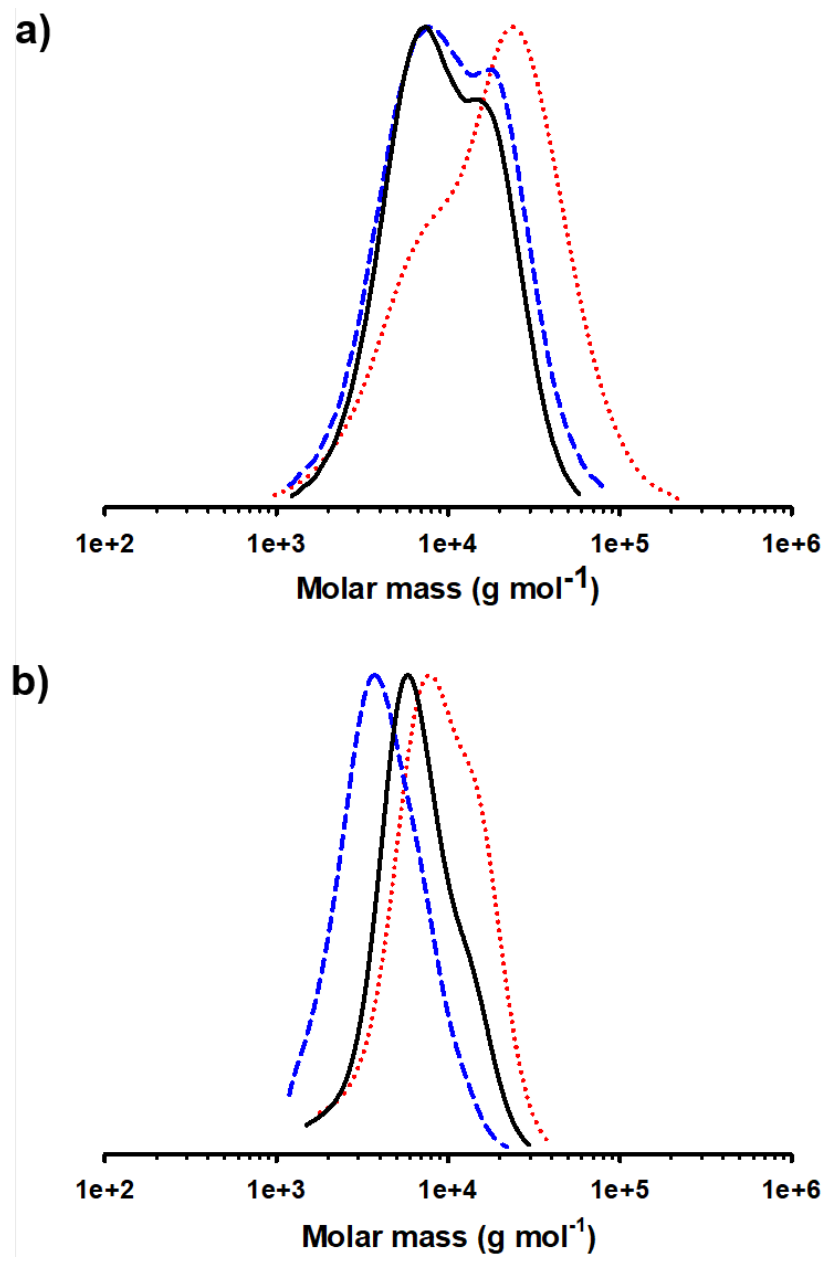

Fig. 5 Normalized SEC traces for polymers (a) grafted on UCNPs and (b) formed in solution prepared from UCNP@CPABD low. HBPs were synthesized using $3 \mathrm{mM}$ (red dotted line) and (b) $6 \mathrm{mM}$ (blue dashed line) of MACPABD, while the preparation of linear polymers was conducted with $3 \mathrm{mM}$ of CPABD (black solid line).

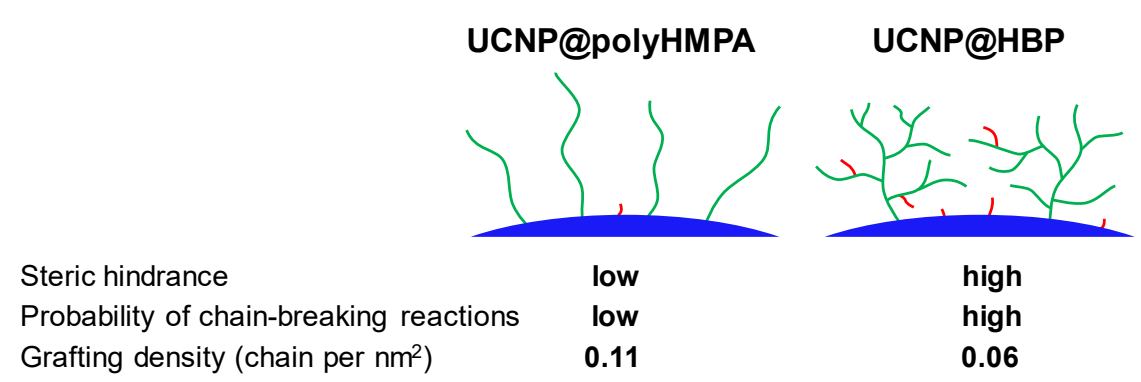

Fig. 6 Growing linear vs hyperbranched polymers from UCNP@CPABD $D_{\text {low }}$ and the influence of steric hindrance, and termination and transfer reactions on their chain propagation. 
a)

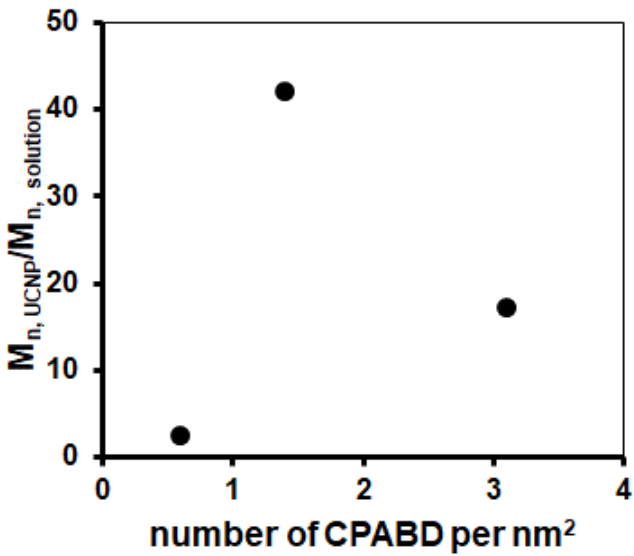

b)

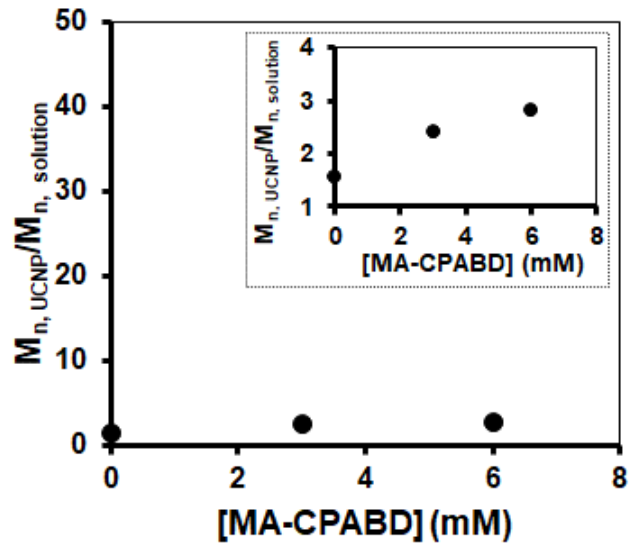

Fig. 7 Comparison of the differences in molecular weight between HBPs grafted on UCNPs and formed in solution for different (a) grafting densities in CPABD on UCNPs using 3 mM of MA-CPABD and (b) concentrations in MA-CPABD using UCNPs with a grafting density of $0.6 \mathrm{CPABD} \mathrm{n^{-2 }}$ (zoom on a reduced scale in inset).

To further investigate these coupling reactions, the grafting density in polymer chains per surface area of UCNPs was determined after 6 and $24 \mathrm{~h}$ of polymerization. The grafting density of the HBP was estimated as 0.35 chain per $\mathrm{nm}^{2}$ after $6 \mathrm{~h}\left(\mathrm{M}_{\mathrm{n}}=2.6 \mathrm{~kg} \mathrm{~mol}^{-1}, \emptyset=1.16\right)$ and 0.10 chain per $\mathrm{nm}^{2}$ after $24 \mathrm{~h}\left(\mathrm{M}_{\mathrm{n}}=13.4 \mathrm{~kg} \mathrm{~mol}^{-1}, Ð=2.72\right)$. This decrease in grafting density suggested the high propensity of termination and transfer reactions. Tsujii et al. proposed for the growth of linear polymers by RAFT polymerization from a flat surface that the decrease of the grafting density could be attributed to the high rate of termination reaction at the early stage of the polymerization. ${ }^{42}$ However, for the synthesis of HBP, this phenomenon could be worsened due to steric hindrance. Furthermore, hopping and rolling mechanisms for surface-initiated RAFT polymerization and the coupling between hyperbranched propagating chains (e.g. between HBP formed in solution and those growing at the surface of UCNPs) could also contribute to this phenomenon (Fig. 8). ${ }^{41}$ 


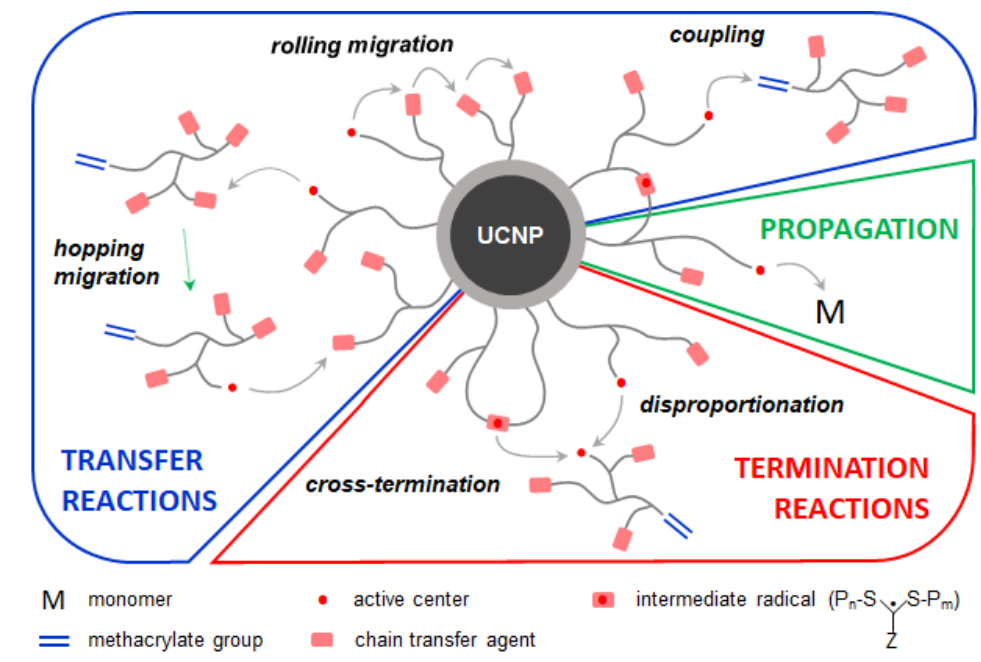

Fig. 8 Summary highlighting all the reactions involved in self-condensing vinyl RAFT polymerization from the surface of UCNPS.

\section{Luminescence properties of UCNP@HBP}

The optical activity of UCNP@HBP dispersed at a concentration of $2 \mathrm{mg} \mathrm{mL}^{-1}$ in water upon a $980 \mathrm{~nm}$ excitation was confirmed. The expected characteristic peak maxima of UCNPs doped with $\mathrm{Er}^{3+}$ were observed at $409 \mathrm{~nm}\left({ }^{4} \mathrm{H}_{9 / 2} \rightarrow{ }^{4} \mathrm{I}_{15 / 2}\right), 542 \mathrm{~nm}\left({ }^{4} \mathrm{H}_{11 / 2} \rightarrow{ }^{4} \mathrm{I}_{15 / 2}\right), 552 \mathrm{~nm}\left({ }^{4} \mathrm{~S}_{3 / 2} \rightarrow{ }^{4} \mathrm{I}_{15 / 2}\right)$, and $654 \mathrm{~nm}\left({ }^{4} \mathrm{~F}_{9 / 2} \rightarrow{ }^{4} \mathrm{I}_{15 / 2}\right)$. The comparison of the normalized luminescence intensity of UCNP@HBP with UCNP@OA dispersed in cyclohexane (Figure 9a) revealed that the red-to-green ratio of the red emission (657 nm) to the green emission (542 nm) intensity was higher for UCNP@HBP as compared to the one of UCNP@OA. This phenomenon is characteristic of the quenching of the green emissive state of the $\mathrm{Er}^{3+}$ ions by water molecules that establish non-radiative relaxation channels. ${ }^{50}$ Surprisingly, the dispersion of UCNP@OA in cyclohexane was globally less bright (by a factor of 3) as compared to aqueous dispersion of UCNP@NH 2 and UCNP@HBP (Fig. S10). The heterogeneity of UCNP@ $\mathrm{NH}_{2}$ and UCNP@HBP dispersions in water observed by DLS (Fig. S11) that could be attributed to the aging of the dispersions may contribute to this observation. 

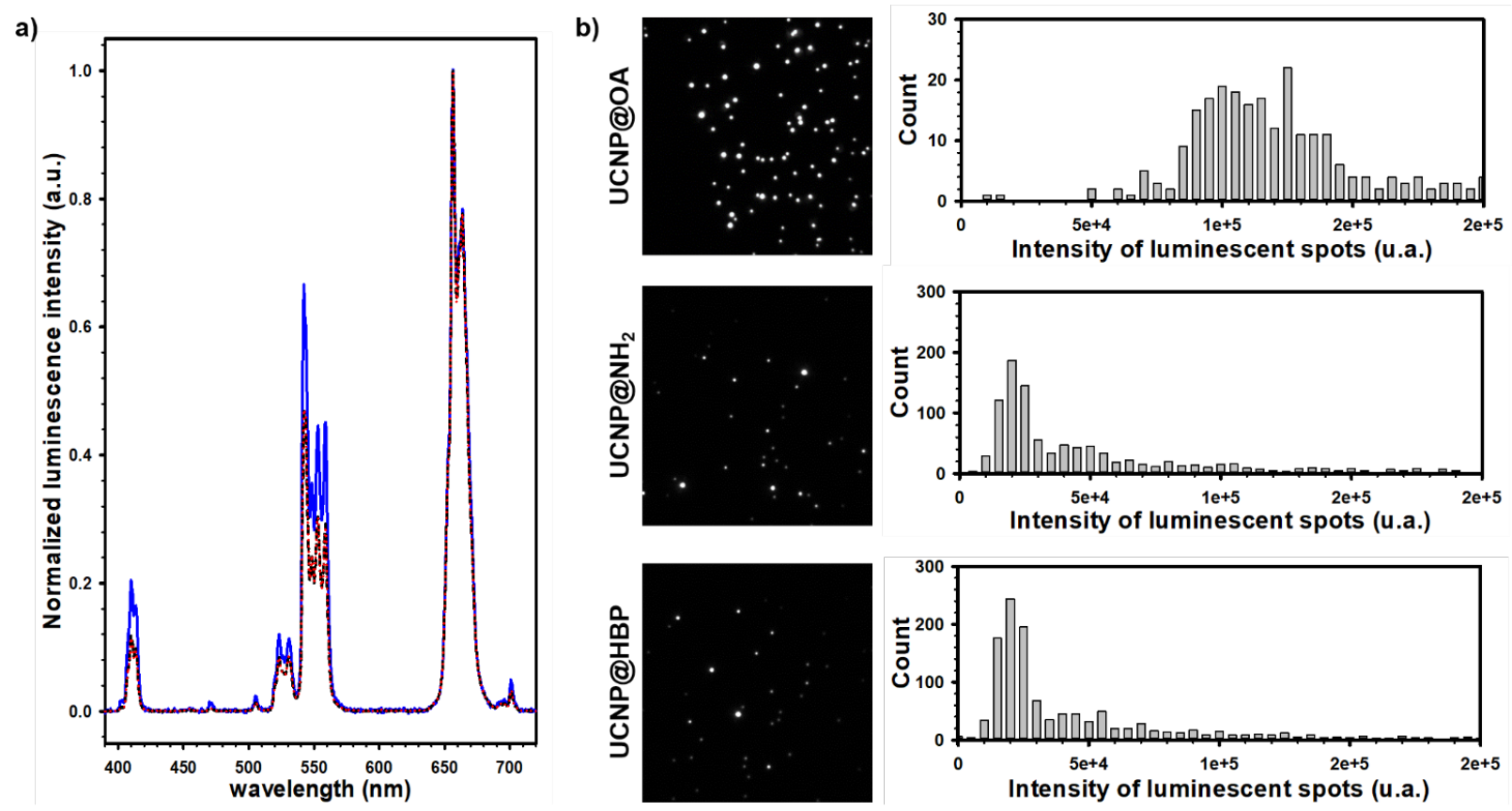

Fig. 9 Luminescence properties of UCNPs solutions at a concentration of $2 \mathrm{mg} \mathrm{mL}^{-1}$ in water (except UCNP@OA in cyclohexane) excited at $980 \mathrm{~nm}$ : (a) luminescence spectrum of dispersion of UCNP@OA (blue solid line), UCNP@NH2 (black dashed line), and UCNP@HBP (red dotted line) in solution normalized at $657 \mathrm{~nm}$ and (b) on the left, representative luminescence microscopy images $\left(46 \times 46 \mu \mathrm{m}^{2}\right)$ and on the right, the corresponding intensity distribution of luminescent spots obtained from luminescence microscopy images for UCNP@OA, UCNP@NH2, and UCNP@HBP.

Single particle microcopy experiments (Figure 9b) were conducted by immobilizing the nanoparticles on microscopy cover glasses. For UCNP@OA a sample highly diluted in cyclohexane was dried on a cover glass, whereas for UCNP@NH $\mathrm{N}_{2}$ and UCNP@HBP experiments were performed in aqueous conditions by electrostatically immobilizing the particles on poly(ethylene imine)-coated cover glasses using highly diluted solutions. For the dispersions in water (i.e. UCNP@NH $\mathrm{N}_{2}$ and UCNP@HBP), 1 mM of NaF was added to prevent the potential dissolution of UCNPs during their imaging. ${ }^{51}$ To decrease the number of aggregates in the field of view (which severely limit the dynamic range of the images due to saturation and bleeding effects) the supernatant of a 1000-fold dilution centrifuged at $2000 \mathrm{~g}$ for $5 \mathrm{~min}$ was used. All samples were imaged on the same wide-field upconversion microscope using the same experimental parameters. For each sample, forty-nine images were acquired and analyzed to extract the intensity of diffraction limited luminescent spots. The histogram of UCNP@OA showed a single population with a luminescence intensity of $\sim 10^{5}$ a.u. with few brighter outliers attributed to the drying process, and notably the coffee-ring effect, producing a non-homogeneous distribution of UCNPs over the cover surface, and formation of small bright aggregates. The histograms of UCNP@NH 2 and UCNP@HBP were very similar a main population with a luminescence intensity of $\sim 2.10^{4}$ a.u and a sub-population with a luminescence intensity of $\sim 4.10^{4} \mathrm{a}$.u. It is hypothesized that the brighter subpopulation consisted of either UCNP dimers, or two single particles that 
adsorbed close to each other, whereas the brighter tail could be attributed to higher order multimers. Overall it seems that the brightness of UCNP@NH 2 and UCNP@HBP were similar and about five times lower than the brightness of UCNP@OA. However, such a direct comparison may not be fully valid due to the fact that the direct environment affects the optical properties of nano-emitters. ${ }^{52}$ UCNP@ $\mathrm{NH}_{2}$ and UCNP@HBP were at the interface water-poly(ethylene imine), while UCNP@OA were at the interface air-glass. Moreover, the centrifugation step used for the preparation of water dispersible samples, may also bias the results by favoring small and less bright UCNPs. Nevertheless, our data clearly showed that UCNP@HBP had a strong emission and single UCNPs could be easily detected by wide-field upconversion microscopy.

\section{SUMMARY}

Surface-initiated self-condensing vinyl RAFT copolymerization of HMPA from the surface of UCNP was investigated. Homopolymerization of HPMA was first conducted to identify the suitable polymerization conditions before attempting the synthesis of HBPs by copolymerization with MA-CPABD. The preparation of HBPs from UCNPs was challenging yielding to grafted HBPs of molecular weight and dispersity higher than expected. These phenomena were attributed to a) the increased concentration in propagating chains at the surface of UCNPs due to the formation of HBPs by SCVP, b) the close proximity of the propagating chains due to their immobilization on the nanoparticles, and c) the fact that RAFT polymerization from a surface was more prone to migration of the active center through hopping and rolling mechanisms. These UCNP@HBP exhibited strong emission comforting their potential use for biomedical imaging and theranostics.

\section{EXPERIMENTAL}

\section{Materials}

Yttrium(III) chloride hexahydrate (99.99\%), ytterbium(III) chloride hexahydrate (99.99\%), erbium(III) chloride hexahydrate (99.99\%), oleic acid (OA, technical grade, 90\%), 1-octadecene (technical grade, 90\%), sodium hydroxide (anhydrous, ACS reagent, $\geq 97 \%$ ), ammo-nium fluoride (ACS reagent, $\geq 98.0 \%$, IGEPAL ${ }^{\circledR}$ CO-520, tetraethyl-orthosilicate (TEOS, 98\%), (3-aminopropyl)triethoxysilane (APTES, 98\%), 1-hydroxybenzotriazole hydrate (HOBt, $\geq 97 \%$ ), 2,2'-azo-bis(isobutyronitrile) (AIBN, 98\%), N,N'-dicyclohexylcarbodiimide (DCC, 99\%), 4-(dimethylamino)pyridine (DMAP, 99\%), 4-cyano-4-(thiobenzoylthio)pentanoic acid (CPABD, $>98 \%$ ), ammonium hydroxide (28\%), silica gel (high-purity grade, pore size $60 \AA$, 230-400 mesh), $\mathrm{N}, \mathrm{N}$-dimethylformamide anhydrous, (DMF, 99.8\%), anhydrous methanol ( $\mathrm{MeOH}, 99.8 \%$ ), anhydrous dichloromethane (DCM, $\geq 99.8 \%)$ were purchased from Sigma-Aldrich. $N, N, N^{\prime}, N^{\prime}-$ Tetramethyl-O-(1H-benzotriazol-1-yl)uronium hexafluorophosphate (HBTU, 99\%) was purchased 
from Iris Biotech. 2-Hydroxyethyl methacrylate (HEMA, 98\%) was purchased from ABCR. N-Ethyldiisopropylamine (DIPEA, 99\%), 1,4-dioxane ( $\geq 99.5 \%)$ were purchased from Alfa Aesar. Hydrofluoric acid ( $\mathrm{HF}, 40 \%$ in $\mathrm{H}_{2} \mathrm{O}$ ) was purchased from Ridel de Haen. Ethanol (absolute, 99.99\%), cyclohexane (99.8\%), and acetone (99.8\%) were purchased from Carlo Erba. Dialysis tubing (regenerated cellulose, MWCO of $1 \mathrm{kDa}$, SpectrumLab) was purchased from Roth. All chemicals were used as received, except if noted otherwise. AIBN was recrystallized twice from ethanol. N-(2-Hydroxypropyl) methacrylamide ${ }^{53}$ (HPMA) and 2-(methacryloyloxy)ethyl 4-cyano4-(phenylcarbonothioylthio) pentanoate ${ }^{35}$ (MA-CPABD) were synthesized as reported in the literature.

\section{Characterizations}

Dynamic light scattering (DLS) experiments were performed on a Malvern Zetasizer Nano ZS at $633 \mathrm{~nm}$ (He-Ne laser beam) with a scattering angle fixed at $173^{\circ}$ at $25^{\circ} \mathrm{C}$. Before measurement, the solutions were filtered through a $0.45 \mu \mathrm{m}$ syringe filter.

Transmission electron microscopy (TEM) images were obtained using a Technai G2 microscope (FEI) at $200 \mathrm{kV} .5 \mu \mathrm{L}$ of the UCNP suspension was deposited onto a freshly glow discharged carbon-covered copper grid (400 mesh). The suspension was left for $2 \mathrm{~min}$ and the excess removed by using a filter paper. Images were acquired with an Eagle2K ssCCD camera (FEI). The size and size distribution of UCNPs were determined based on at least 29 nanoparticles using the ImageJ software (Version 1.51n, Wayne Rasband, National Institutes of Health, USA).

Fourier transform infrared (FTIR) spectra were recorded on a Bruker Vertex 70 spectrometer using the attenuated total reflectance (ATR) technique between 500 and $4000 \mathrm{~cm}^{-1}$.

Nitrogen adsorption/desorption isotherms according to the Brunauer-Emmett-Teller (BET) theory were recorded on a Micromeritics TriStar 3000 V6.07A analyzer. The samples were degassed at $150{ }^{\circ} \mathrm{C}$ for $3 \mathrm{~h}$ in the degassing port of the adsorption apparatus.

UV-vis spectroscopy was carried out using a Perkin Elmer Lambda 25 spectrophotometer.

Thermogravimetric analyses (TGA) were performed on a Mettler-Toledo TGA2 thermogravimeter at a heating scan rate of $10{ }^{\circ} \mathrm{C} \mathrm{min}^{-1}$ under argon (flow rate: $100 \mathrm{~mL} \mathrm{~min}{ }^{-1}$ ) using alumina crucibles.

${ }^{1} \mathrm{H}$ and ${ }^{13} \mathrm{C}$ NMR spectra were recorded in $\mathrm{CDCl}_{3}, \mathrm{DMSO}-\mathrm{d}_{6}, \mathrm{MeOD}$, or $\mathrm{D}_{2} \mathrm{O}$ on a $400 \mathrm{MHz}$ Bruker Avance III HD spectrometers equipped with a BBO type probe at $25^{\circ} \mathrm{C}$.

Size-exclusion chromatography (SEC) was performed on a DIONEX Ultimate 3000 system equipped with a guard column and four Shodex OH-pak columns $(7.5 \times 300 \mathrm{~mm}, 803 \mathrm{HQ}, 804 \mathrm{HQ}$, $806 \mathrm{HQ}, 807 \mathrm{HQ})$, a Wyatt OPTILAB rEX differential refractometer, and a Wyatt DAWN HELEOS II light scattering detector and was operated at $30{ }^{\circ} \mathrm{C}$ using $60 / 40$ water/acetonitrile with $0.1 \mathrm{M}$ $\mathrm{NaNO}_{3}$ as eluent at a flow rate of $0.5 \mathrm{~mL} \mathrm{~min}$. 
Luminescence spectroscopy and luminescence imaging of UCNPs were performed using homemade setups as described in details in our previous work. ${ }^{54}$ For luminescence spectroscopy, the continuous-wave laser beam of a single mode fiber coupled laser diode (Qphotonics, QFBGLD-980-350) was focused in a quartz cuvette (Hellma QS Semi-Micro Cells) with an estimated average excitation intensity in the beam waist of $8 \mathrm{~kW} \mathrm{~cm}^{-2}$. The emission of the sample was collected by a 10x/0.25 numerical aperture objective and detected by a fiber spectrometer (Avantes, AvaSpec-3648). For luminescence microscopy, the same laser source was coupled to an inverted microscope (Olympus IX71) equipped with a high numerical aperture objective (Olympus, UApo N 100x/1.49 Oil) and allowed to excite the UCNPs with an excitation power density of $8 \mathrm{~kW} \mathrm{~cm}^{-2}$ in epi illumination. Luminescence emission was separated from the excitation beam by using a short pass dichroic mirror (Chroma, T875spxrxt), while the residual laser light was removed by a low pass filter (Chroma, E700SP). Emission was detected by an electron multiplying CCD camera (Hamamatsu, ImagEM X2 C9100-23B). Acquisition was fully automated and controlled by scripts within the MicroManager framework. ${ }^{55}$ All static images shown in the article were recorded as an averaged stack of 100 images, each with 30 ms exposure time. Wide-field microscopy images were treated with Image $1.51 \mathrm{~h}$ as part of the FIJ package, ${ }^{56}$ spot fitting was performed with the Gaussian Fit module of the GDSC SMLM package. ${ }^{57}$

\section{Synthesis of $\mathrm{NaYF}_{4} ; \mathrm{Yb} 20 \%$; Er 2\% upconversion nanoparticles with amine groups at their surface (UCNP@NH}

$\mathrm{NaYF}_{4}: 20 \% \mathrm{Yb}^{3+}, 2 \% \mathrm{Er}^{3+}$ nanocrystals having a diameter of 25-30 $\mathrm{nm}$ were prepared by the co-precipitation method according to a previously reported procedure ${ }^{33}$ with some modifications. Briefly, $1 \mathrm{mmol}$ of lanthanide chloride (Y:Yb: $\mathrm{Er}=78: 20: 2)$ were dissolved into a solution of oleic acid $(6 \mathrm{~mL})$ in 1-octadecene $(15 \mathrm{~mL})$ under vigorous stirring and heated to $150{ }^{\circ} \mathrm{C}$ to obtain a homogeneous solution that was then cooled to $30^{\circ} \mathrm{C}$ under argon. A mixture of $\mathrm{NaOH}$ $(0.10 \mathrm{~g}, 2.5 \mathrm{mmol})$ and $\mathrm{NH}_{4} \mathrm{~F}(0.14 \mathrm{~g}, 4.0 \mathrm{mmol})$ dissolved in $5 \mathrm{~mL}$ of $\mathrm{MeOH}$ was then added and stirred for $30 \mathrm{~min}$ at $30{ }^{\circ} \mathrm{C}$. The mixture was then heated at $110^{\circ} \mathrm{C}$ for $50 \mathrm{~min}$ to remove $\mathrm{MeOH}$, then at $290^{\circ} \mathrm{C}$ for $180 \mathrm{~min}$ under argon. The solution was cooled to room temperature and $25 \mathrm{~mL}$ of acetone was added. The precipitate was centrifuged, isolated and redispersed in $20 \mathrm{~mL}$ of cyclohexane. The concentration of the dispersion of $\mathrm{NaYF}_{4}: 20 \% \mathrm{Yb}^{3+}, 2 \% \mathrm{Er}^{3+}$ nanocrystals capped with oleate ligands (UCNP@OA) in cyclohexane was around $40 \mathrm{mg} \mathrm{mL}^{-1}$.

UCNP@OA were modified with silanol (Si-OH) in the presence of TEOS under basic conditions by reverse microemulsion method ${ }^{26,58}$ followed by the introduction of primary amine groups by treating with APTS. ${ }^{34}$ Briefly, $1.5 \mathrm{~g}$ of IGEPAL ${ }^{\circledR}$ CO-520 $(3.33 \mathrm{mmol})$ was charged in a $50 \mathrm{~mL}$ centrifuge tube followed by $21 \mathrm{~mL}$ of cyclohexane and $4 \mathrm{~mL}$ of UCNP@OA dispersion (20 mg mL' ${ }^{1}$ in cyclohexane) were added into the tube. After $1 \mathrm{~min}$ of sonication, the mixture was poured to a $100 \mathrm{~mL}$ flask under vigorous stirring (750 rpm). $0.165 \mathrm{~mL}$ of ammonium hydroxide (28\%) was added slowly and stirred for $30 \mathrm{~min} .50 \mu \mathrm{L}$ of TEOS $(0.22 \mathrm{mmol})$ were added to the reaction 
mixture that was stirred for $24 \mathrm{~h} .30 \mu \mathrm{L}$ of APTS $(152 \mu \mathrm{mol})$ was then added and stirred for $24 \mathrm{~h}$. $50 \mathrm{~mL}$ of a mixture of acetone and ethanol (50:50) was added to the reaction tube. The mixture was centrifuged at $6500 \mathrm{~g}$ for $30 \mathrm{~min}$ at room temperature and the supernatant was discarded. The UCNPs were washed several times with redispersion by vortex and sonication in ethanol and finally with acetone. The nanoparticles were dried under vacuum yielding $140 \mathrm{mg}$ of aminefunctionalized UCNPs. UCNP@ $@ N_{2}$ with a lower amount of amine groups were prepared similarly by adding 7.5 or $15 \mu \mathrm{L}$ of APTS (38 and $76 \mu \mathrm{mol}$ respectively) yielding to 121 and $129 \mathrm{mg}$ of

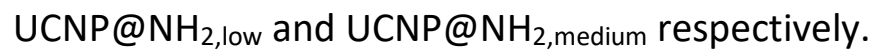

\section{Synthesis of CPABD-functionalized UCNPs (UCNP@CPABD)}

$120 \mathrm{mg}$ of UCNP@ $\mathrm{NH}_{2}$, high were dispersed in $5 \mathrm{~mL}$ of DMF. A solution of HBTU (154 mg, $\left.0.4 \mathrm{mmol}\right)$, HOBt (55 mg, $0.4 \mathrm{mmol}$ ), CPABD (113 mg, $0.4 \mathrm{mmol}$ ) and DIPEA (142 $\mu \mathrm{L}, 0.8 \mathrm{mmol}$ ) in $2 \mathrm{~mL}$ of DMF was added to the dispersion of UCNP@ $\mathrm{NH}_{2}$ under argon. The reaction mixture was stirred vigorously overnight at room temperature. The UCNPs were then collected by centrifugation and washed five times with DMF and three times with acetone by redispersion in the solvent followed by sonication for $10 \mathrm{~s}$. UCNP@CPABD with a high CPABD grafting density (UCNP@CPABD high) was finally dried under vacuum at room temperature for $48 \mathrm{~h}$ affording $115 \mathrm{mg}$ of UCNP@CPABD ${ }_{\text {high }}$ (95\% yield). The preparation of UCNP@CPABD with a medium (UCNP@CPABD medium) and low (UCNP@CPABD $D_{\text {low }}$ ) CPABD grafting density were carried out according to the same protocols using $77 \mathrm{mg}$ of HBTU (0.2 mmol), $22.5 \mathrm{mg}$ of HOBt $(0.2 \mathrm{mmol}), 57 \mathrm{mg}$ of CPABD $(0.2 \mathrm{mmol})$ and $71 \mu \mathrm{L}$ of DIPEA (0.4 mmol) for UCNP@CPABD medium and $39 \mathrm{mg}$ of HBTU $(0.1 \mathrm{mmol}), 12 \mathrm{mg}$ of HOBt (0.1 mmol), $29 \mathrm{mg}$ of CPABD (0.1 mmol) and $40 \mu \mathrm{L}$ of DIPEA (0.2 mmol) for UCNP@CPABD low.

\section{Preparation of polyHPMA from UCNP@CPABD by surface-initiated RAFT polymerization from UCNPs (UCNP@polyHPMA)}

In a $5 \mathrm{~mL}$ round bottom flask, $30 \mathrm{mg}$ of UCNP@CPABD, $250 \mathrm{mg}$ of HPMA (1.7 mmol), $2.52 \mathrm{mg}$ of CPABD $(9 \mu \mathrm{mol}, 3 \mathrm{mM})$, and $3 \mathrm{~mL}$ of solvent (1,4-dioxane, DMF or $\mathrm{MeOH}$ ) were added and dispersed under ultrasonication for $6 \mathrm{~min}$ (three times $2 \mathrm{~min}$ in a cold-water bath). $0.33 \mathrm{mg}$ of AIBN $(2 \mu \mathrm{mol})$ dissolved in 50 ? $\mathrm{L}$ of the solvent used for the polymerization was added to the reaction flask. The reaction mixture was degassed by bubbling argon into the solution for $30 \mathrm{~min}$. The reaction mixture was stirred in an oil bath thermostated at $65^{\circ} \mathrm{C}$. For kinetic studies, aliquots were withdrawn at predetermined intervals during the polymerization to determine the monomer conversion of the polymer formed in solution. HPMA conversion was determined by

${ }^{1} \mathrm{H}$ NMR spectroscopy by comparing the integration of the vinyl protons at $5.7 \mathrm{ppm}$ of HPMA to the integration of the methyl protons at 0.5-1.1 ppm of the backbone of polyHPMA. After $24 \mathrm{~h}$ of reaction, the reaction mixture was then quenched by placing the reaction flask in an ice bath. UCNP@polyHMPA were isolated by centrifugation. The supernatant was collected and precipitated in $\mathrm{Et}_{2} \mathrm{O}$ to isolate the polymer formed in solution. UCNP@CPABD were further 
purified by performing cycles of centrifugation and redispersion in $\mathrm{MeOH}$ (five times) and acetone (twice) to remove any ungrafted polymer. The polymers formed in solution and at the surface of UCNPs (UCNP@polyHMPA) were dried under vacuum at room temperature for $48 \mathrm{~h}$.

\section{Preparation of HBP from UCNP@CPABD by surface-initiated RAFT copolymerization (UCNP@HBP)}

30 mg of UCNP@CPABD, 250 mg of HPMA (1.7 mmol), 3.52 mg of MA-CPABD (90 $\mu \mathrm{mol})$, and $3 \mathrm{~mL}$ of 1,4-dioxane were placed in a $5 \mathrm{~mL}$ bottom flask and dispersed under ultrasonication for $6 \mathrm{~min}(2 \mathrm{~min} \times 3)$ in a water bath at $10{ }^{\circ} \mathrm{C} .0 .33 \mathrm{mg}$ of AIBN $(2 \mu \mathrm{mol})$ dissolved in $50 \mu \mathrm{L}$ of 1,4-dioxane was added the reaction mixture. The reaction mixture was degassed by bubbling argon into the solution for $30 \mathrm{~min}$. The reaction mixture was stirred in an oil bath thermostated at $65{ }^{\circ} \mathrm{C}$. For kinetic studies, aliquots were withdrawn at predetermined intervals during the polymerization to determine the monomer conversion of the polymer formed in solution. After $24 \mathrm{~h}$ of reaction, the reaction mixture was then quenched by placing the reaction flask in an ice bath. UCNP@HBP were isolated by centrifugation, $\mathrm{MeOH}$ was added to redisperse the nanoparticles and centrifuged again. The supernatant was collected after each washing step. The degree of branching (DB), monomer conversion and molecular weight of the polymer formed in solution were determined by UV-vis spectroscopy, ${ }^{1} \mathrm{H}$ NMR spectroscopy, and SEC measurement respectively. UCNP@HBP were further purified by performing cycles of centrifugation and redispersion three times in successively 1,4-dioxane, $\mathrm{MeOH}$, and acetone to remove any ungrafted polymer. The polymers formed in solution $\left(\mathrm{HBP}_{\text {sol }}\right)$ and at the surface of UCNPs (UCNP@HBP) were dried under vacuum at room temperature for $48 \mathrm{~h}$. The UCNPs were dried under vacuum at room temperature for $48 \mathrm{~h}$.

\section{Cleavage of the polymers from the surface of UCNPS}

$30 \mathrm{mg}$ of UCNP@polymer dispersed in $2.5 \mathrm{~mL}$ of deionized water were sonicated for 2 min before adding $0.5 \mathrm{~mL}$ of $40 \% \mathrm{HF}$ (Caution: HF is highly corrosive). The solution was shaken for $4 \mathrm{~h}$ and then neutralized by adding very slowly a saturated solution of $\mathrm{NaHCO}_{3}$. The mixture was dialyzed against water for 2 days and then centrifuged to collect the supernatant that was lyophilized.

\section{Monitoring of CPABD concentration by UV-vis spectroscopy}

For accurate comparison, a stock solution of CPABD was prepared using one part for the polymerization and another part as control. After polymerization, the supernatant was collected from the washing steps and concentrated by rotary evaporation. The pink residue was dissolved in $5 \mathrm{~mL}$ of $\mathrm{MeOH}$ and the solutions were characterized by UV-vis spectroscopy.

\section{CONFLICTS OF INTEREST}

There are no conflicts to declare. 


\section{ACKNOWLEDGEMENTS}

This work was financially supported by the CNRS and the University of Strasbourg. The doctoral position of AK is supported by the University of Strasbourg through a doctoral contract from the Physics and Chemistry-Physics doctoral school. The authors are thankful to C. Foussat, M. Legros, M. Lenertz, F. Vigneron for SEC, TGA, XRD and BET measurements respectively, and M. Schmutz for fruitful discussions. The authors thank the polymer characterization facilities at the Institut Charles Sadron, the electron microscopy facilities at the Institut Charles Sadron, and the Cronenbourg NMR core facilities. YM is grateful to the Institut Universitaire de France (IUF) for support and providing additional time to be dedicated to research.

\section{REFERENCES}

1 M. Hood, M. Mari and R. Muñoz-Espí, Materials, 2014, 7, 4057-4087.

2 R. Francis, N. Joy, E. P. Aparna and R. Vijayan, Polym. Rev., 2014, 54, 268-347.

3 R. Jordan, N. West, A. Ulman, Y.-M. Chou and O. Nuyken, Macromolecules, 2001, 34, 16061611.

4 R. Zirbs, W. Binder, M. Gahleitner and D. Machl, Macromol. Symp., 2007, 254, 93-96.

5 Q. Zhou, S. Wang, X. Fan, R. Advincula and J. Mays, Langmuir, 2002, 18, 3324-3331.

6 E. Hübner, J. r. Allgaier, M. Meyer, J. r. Stellbrink, W. Pyckhout-Hintzen and D. Richter, Macromolecules, 2010, 43, 856-867.

7 J. O. Zoppe, N. C. Ataman, P. Mocny, J. Wang, J. Moraes and H.-A. Klok, Chem. Rev., 2017, 117, 1105-1318.

8 S. Kango, S. Kalia, A. Celli, J. Njuguna, Y. Habibi and R. Kumar, Prog. Polym. Sci., 2013, 38, 1232-1261.

9 K. G. Neoh and E. T. Kang, Polym. Chem., 2011, 2, 747-759.

10 G. Chen, H. Qiu, P. N. Prasad and X. Chen, Chem. Rev., 2014, 114, 5161-5214.

11 F. Auzel, Chemical Reviews, 2003, 104, 139-174.

12 F. Wang, D. Banerjee, Y. Liu, X. Chen and X. Liu, Analyst, 2010, 135, 1839-1854.

13 N. J. J. Johnson, N. M. Sangeetha, J.-C. Boyer and F. C. J. M. van Veggel, Nanoscale, 2010, 2, 771-777.

14 J.-C. Boyer, M.-P. Manseau, J. I. Murray and F. C. J. M. van Veggel, Langmuir, 2010, 26, 11571164.

15 S. Beyazit, S. Ambrosini, N. Marchyk, E. Palo, V. Kale, T. Soukka, B. Tse Sum Bui and K. Haupt, Angew. Chem. Int. Ed., 2014, 53, 8919-8923.

16 L. Zhou, B. He, J. Huang, Z. Cheng, X. Xu and C. Wei, ACS Appl. Mater. Interfaces, 2014, 6, 7719-7727.

17 B. He and L. Zhou, RSC Adv., 2015, 5, 97764-97772.

18 A. Bagheri, H. Arandiyan, N. N. M. Adnan, C. Boyer and M. Lim, Macromolecules, 2017, 50, 7137-7147.

19 J. Xiang, X. Tong, F. Shi, Q. Yan, B. Yu and Y. Zhao, J. Mater. Chem. B, 2018, 6, 3531-3540. 
20 J. M. Fréchet, M. Henmi, I. Gitsov, S. Aoshima, M. R. Leduc and R. B. Grubbs, Science, 1995, 269, 1080-1083.

21 X. Wang and H. Gao, Polymers, 2017, 9, 188.

22 P. Bharathi and J. S. Moore, Macromolecules, 2000, 33, 3212-3218.

23 P. Liu and T. Wang, Polym. Eng. Sci., 2007, 47, 1296-1301.

24 C. Schüll and H. Frey, Polymer, 2013, 54, 5443-5455.

25 Z. Li and Y. Zhang, Angew. Chem. Int. Ed., 2006, 45, 7732-7735.

26 R. Abdul Jalil and Y. Zhang, Biomaterials, 2008, 29, 4122-4128.

27 E. Kaiser, R. L. Colescott, C. D. Bossinger and P. I. Cook, Anal. Biochem., 1970, 34, 595-598.

28 Z. Duan, Z. Qu, F. Hu, Y. Yang, G. Chen and H. Xu, Appl. Surf. Sci., 2014, 300, 104-110.

29 C.-H. Liu and C.-Y. Pan, Polymer, 2007, 48, 3679-3685.

30 R. Duncan, Nat. Rev. Drug Discov., 2003, 2, 347-360.

31 P. Chytil, E. Koziolová, T. Etrych and K. Ulbrich, Macromol. Biosci., 2018, 18, 1700209.

32 S. Das, M. Banik, G. Chen, S. Sinha and R. Mukherjee, Soft Matter, 2015, 11, 8550-8583.

33 S. Turgman-Cohen and J. Genzer, Macromolecules, 2010, 43, 9567-9577.

34 X. Pan, F. Zhang, B. Choi, Y. Luo, X. Guo, A. Feng and S. H. Thang, Eur. Polym. J., 2019, 115, 166-172.

35 Z. Wei, X. Hao, P. A. Kambouris, Z. Gan and T. C. Hughes, Polymer, 2012, 53, 1429-1436.

36 K. Skrabania, A. Miasnikova, A. M. Bivigou-Koumba, D. Zehm and A. Laschewsky, Polym. Chem., 2011, 2, 2074-2083.

37 J. A. Alfurhood, P. R. Bachler and B. S. Sumerlin, Polym. Chem., 2016, 7, 3361-3369.

38 D. Hölter, A. Burgath and H. Frey, Acta Polym., 1997, 48, 30-35.

39 Y. Zheng, L. Wang, L. Lu, Q. Wang and B. C. Benicewicz, ACS Omega, 2017, 2, 3399-3405.

40 D. Yan, A. H. E. Müller and K. Matyjaszewski, Macromolecules, 1997, 30, 7024-7033.

41 D. Zhou, E. Mastan and S. Zhu, Macromol. Theory Simul., 2012, 21, 602-614.

42 Y. Tsujii, M. Ejaz, K. Sato, A. Goto and T. Fukuda, Macromolecules, 2001, 34, 8872-8878.

43 K. Ohno, Y. Ma, Y. Huang, C. Mori, Y. Yahata, Y. Tsujii, T. Maschmeyer, J. Moraes and S. Perrier, Macromolecules, 2011, 44, 8944-8953.

44 P. F. W. Simon and A. H. E. Müller, Macromolecules, 2001, 34, 6206-6213.

45 H. Mori, D. Chan Seng, H. Lechner, M. Zhang and A. H. E. Müller, Macromolecules, 2002, 35, 9270-9281.

46 C. Li and B. C. Benicewicz, Macromolecules, 2005, 38, 5929-5936.

47 S. Turgman-Cohen and J. Genzer, J. Am. Chem. Soc., 2011, 133, 17567-17569.

48 Y. Kwak, A. Goto, Y. Tsujii, Y. Murata, K. Komatsu and T. Fukuda, Macromolecules, 2002, 35, 3026-3029.

49 D. Li, Y. Luo, B.-G. Li and S. Zhu, J. Polym. Sci. Part A: Polym. Chem., 2008, 46, 970-978.

50 R. Arppe, I. Hyppänen, N. Perälä, R. Peltomaa, M. Kaiser, C. Würth, S. Christ, U. Resch-Genger, M. Schäferling and T. Soukka, Nanoscale, 2015, 7, 11746-11757.

51 O. Dukhno, F. Przybilla, V. Muhr, M. Buchner, T. Hirsch and Y. Mély, Nanoscale, 2018, 10, 15904-15910.

52 L. Novotny and B. Hecht, Principles of Nano-Optics, Cambridge University Press, Cambridge, 2012. 
53 K. Ulbrich, V. Šubr, J. Strohalm, D. Plocová, M. Jelínková and B. Říhová, J. Controlled Release, 2000, 64, 63-79.

54 O. Dukhno, F. Przybilla, V. Muhr, M. Buchner, T. Hirsch and Y. Mély, Nanoscale, 2018, 10, 15904-15910.

55 A. D. Edelstein, M. A. Tsuchida, N. Amodaj, H. Pinkard, R. D. Vale and N. Stuurman, J. Biol. Methods, 2014, 1, e10.

56 J. Schindelin, I. Arganda-Carreras, E. Frise, V. Kaynig, M. Longair, T. Pietzsch, S. Preibisch, C. Rueden, S. Saalfeld, B. Schmid, J.-Y. Tinevez, D. J. White, V. Hartenstein, K. Eliceiri, P. Tomancak and A. Cardona, Nat. Methods, 2012, 9, 676-682.

57 GDSC ImageJ plugins, University of Sussex, http://www.sussex.ac.uk/gdsc/intranet/microscopy/imagej/gdsc plugins (accessed March 29, 2018)

58 M. K. Gnanasammandhan, N. M. Idris, A. Bansal, K. Huang and Y. Zhang, Nat. Protoc., 2016, 11, 688-713. 